\title{
MUDANÇAS NA GESTÃO DO TRABALHO NO BRASIL: LEVANTAMENTO DE DIFERENTES VISÕES
}

\section{CHANGES IN HUMAN RESOURCES MANAGEMENT IN BRAZIL: SURVEY OF DIFFERENTS VISIONS}

\author{
Marcelo Weishaupt Proni ${ }^{1}$; Patricia da Conceição ${ }^{2}$ \\ ${ }^{1}$ Universidade Estadual de Campinas - Unicamp - Campinas - Brasil \\ mwproni@eco.unicamp.br \\ ${ }^{2}$ Bolsista do $\mathrm{CNPq}$ - Brasil \\ patricia.conc@,zipmail.com.br
}

\begin{abstract}
Resumo
O propósito deste texto é identificar os principais argumentos que têm sido levantados no debate nacional relacionado com os impactos da introdução de inovações tecnológicas elou organizacionais sobre o trabalho em grandes empresas. A análise examina cinco afirmativas: (i) as inovações tecnológicas exigem a adoção de um modelo flexível de organização do trabalho; (ii) o papel do Departamento de Recursos Humanos tem se limitado a adaptar os trabalhadores aos novos requisitos da produção; (iii) os métodos de gestão do trabalho no setor industrial são diferentes dos adotados no setor serviços; (iv) as principais conseqüências dos novos métodos de gestão do trabalho são desfavoráveis para os empregados de grandes empresas; (v) a gestão flexível do trabalho induziu mudanças que afetam outras dimensões da vida social.
\end{abstract}

Palavras-chave: inovação tecnológica; cultura organizacional; gestão do trabalho.

\section{Introdução}

Nos países desenvolvidos, desde o final da década de 70 e o início dos anos 80, foram sendo implementadas mudanças nas estratégias de concorrência e de gestão das empresas, num contexto de inovações tecnológicas e de incertezas sobre o desenvolvimento macroeconômico, incentivando a adoção de experiências de reestruturação empresarial, em particular no campo industrial e no campo dos serviços modernos. Segundo alguns autores, a Terceira Revolução Industrial, a globalização econômica e a liberalização dos mercados financeiros internacionais mudaram o próprio padrão de concorrência intercapitalista, pressionando as grandes empresas a adotar medidas para aumentar a competitividade, buscando mais agilidade e eficiência no processo produtivo e na distribuição, assim como reduzir o custo do trabalho (Coutinho, 1992). 
$\mathrm{Na}$ economia globalizada, as empresas mais dinâmicas e inseridas em mercados externos começaram a experimentar um novo modelo de gestão dos negócios, adequado às características de organizações transnacionais, que precisam obter vantagens comparativas e explorar ao máximo todos os benefícios da expansão global. Ao mesmo tempo, a transformação do cenário empresarial tem modificado a organização do processo de trabalho. Nesse sentido, pode-se afirmar que o antigo fordismo - entendido como padrão de organização do trabalho e produção - passou a combinar-se com ou ser substituído pela flexibilização dos processos de trabalho e produção, dando lugar a um padrão mais compatível com as novas exigências do mercado mundial, combinando produtividade, capacidade de inovação e competitividade (Ianni, 1996).

O surgimento de novos setores produtivos e de inovações comerciais, tecnológicas e organizacionais, de um lado, e a expansão dos mercados financeiros com menor ritmo de crescimento econômico, de outro, tiveram várias conseqüências sobre o funcionamento dos mercados de trabalho nacionais. Junto com o persistente e alto desemprego, verificou-se uma tendência à redução no quadro de pessoal e nas hierarquias das grandes empresas, assim como se acentuou a busca por maior flexibilização das relações de trabalho, contribuindo para gerar uma crescente insegurança no mundo do trabalho (Mattoso, 1995).

A adoção de novas tecnologias (em particular a automação industrial e a microeletrônica) e a adoção de novas formas de organização do trabalho (just-in-time, qualidade total, etc.) foram as formas preferidas de resposta das empresas líderes ao novo contexto da concorrência intercapitalista (Meireles Filho, 1998). Contudo, não devemos imaginar que houve aí um determinismo em relação aos impactos desse processo sobre as condições de trabalho e a organização dos trabalhadores, uma vez que os sindicatos exerceram uma influência, maior ou menor de acordo com o país, na definição do ritmo e extensão da introdução de tais inovações (Freyssinet, 1998).

Por outro lado, o avanço do neoliberalismo e o enfraquecimento das forças sociais que defendem a manutenção dos controles públicos dos mercados, assim como dos direitos sociais (ou o chamado Welfare State), tornam mais fácil a revisão da legislação trabalhista e a flexibilização das relações de trabalho. Mas, não podemos deixar de registrar que a racionalização econômica não afetou com a mesma intensidade a proteção aos trabalhadores nos principais países capitalistas avançados (Dedecca, 1999).

Não se pode esquecer que há autores que enfatizam a conformação de uma sociedade informatizada, com circulação mais rápida de informação e de conhecimento, o que possibilitou o surgimento de grandes empresas que operam em rede (on line) e trouxe uma série de consequências em termos de configuração da vida social (Castells, 2000). Entre outras consequências, a "sociedade informacional" tem mudado a forma de operar das empresas e tem aumentado as exigências de qualificação para trabalhar nos departamentos responsáveis por alimentar essas "redes", agilizando 
trocas e comunicações. Também nessa abordagem, a reestruturação empresarial acabou tendo impactos prejudiciais sobre o mundo do trabalho, provocando uma maior polarização e fragmentação social.

Acrescente-se que, no novo contexto, o trabalho industrial não se organiza mais na interface do operador/máquina/posto de trabalho, na qual os tempos e gestos podem ser facilmente programados e controlados. Tornam-se imprescindíveis o trabalho em equipe, os tempos compartilhados, a troca constante de informação e a participação dos trabalhadores na gestão da produção. Procura-se a todo custo a eliminação dos tempos perdidos com a preparação das máquinas, com limpeza e manutenção e com outras interrupções, buscando o máximo de produtividade. Dessa maneira, o operário é estimulado a intervir no processo para prevenir problemas. A produtividade da empresa não está mais assentada na rapidez dos gestos e movimentos próprios do taylorismo/fordismo, mas na rapidez de planejamento e na resolução dos problemas que surgem em diferentes situações (Neves, 1998).

Em suma, na era da informação e da globalização, a estrutura organizacional das grandes empresas passou por profundas mudanças, que implicaram a preferência por trabalhadores polivalentes e por equipes multifuncionais de trabalho, com metas bem definidas, mas sem a segurança no emprego que caracterizava o período anterior. E parece haver um consenso de que a adoção de novas tecnologias e a adoção de novas formas de organização do trabalho não só afetaram as condições de trabalho como alteraram a forma de subordinação (e a capacidade de negociação) dos trabalhadores.

Neste renovado contexto empresarial, passou a predominar um novo discurso entre os responsáveis pela gestão do trabalho. Na medida em que o "recurso" mais importante para o sucesso da empresa inserida num mercado em constante mudança passou a ser o conhecimento, a antiga Administração de Recursos Humanos cedeu lugar a uma nova abordagem: a Gestão de Pessoas (Chiavenato, 2002). Desde os anos 80, quando avança a globalização econômica, o discurso dos gurus da administração, condicionado pelas as mudanças na organização do trabalho em razão das inovações tecnológicas e organizacionais, passou a enfatizar a necessidade de adotar novas diretrizes na gestão de recursos humanos, assim como a importância da qualificação profissional para a competitividade das empresas (Fleury et al., 1990). Pouco a pouco, vai ganhando adeptos a valorização das competências individuais, ao passo que vai se difundindo o conceito de empregabilidade e começa a ser veiculada a idéia de liderança compartilhada. A proposição de novos modelos de gestão de pessoas foi freqüente ao longo dos anos 90 (Neri, 1999; Wood Jr., 2001).

Contudo, foram surgindo leituras críticas do discurso que enaltece a transformação dos trabalhadores em "parceiros" ou "colaboradores", assim como a pretensa autonomia destes na nova 
distribuição de poder dentro das empresas. Um tipo de crítica é aquela que denuncia a desumanização dos "recursos humanos", ou melhor, a degradação das relações humanas numa sociedade que absorve cada vez mais os princípios do mercado como norteadores das normas que regulam o mundo do trabalho (Ackerman, 1998). Outro tipo de crítica, indo numa direção semelhante, é a que destaca o fato de as novas formas de gestão e cultura empresarial desenvolverem uma forma velada de controle baseada na subjetividade do trabalhador, que mina os laços de solidariedade (Neves, 1998). No limite, o capitalismo contemporâneo e suas empresas flexíveis vêm formatando a própria personalidade dos trabalhadores que se adaptam aos novos empregos, deixando as pessoas psicologicamente "à deriva" em razão da insegurança cotidiana e produzindo comportamentos socialmente conservadores (Sennett, 2000).

Também deve ser lembrado nesse debate o argumento que afirma serem diferentes as condições de implementação dos novos modelos de gestão, conforme a evolução do cenário econômico, a força política dos sindicatos e o quadro jurídico-institucional. Nesse sentido, é importante frisar que a flexibilização das relações de trabalho, no Brasil, tendeu a deteriorar as condições de trabalho numa amplitude muito maior do que nos países desenvolvidos, abrindo uma grande margem de manobra para a implementação, no interior das empresas, de normas e programas autoritários, que não foram objeto de negociação com os respectivos sindicatos (Carvalho Neto e Parreiras de Oliveira, 1998).

Portanto, a contrapartida do processo de reestruturação empresarial tem sido a terceirização das atividades, a subcontratação e a diminuição da base sindical, de um lado, e o ataque aos direitos trabalhistas e uma postura limitadamente defensiva por parte das categorias melhor organizadas, de outro. Verificou-se uma exclusão dos sindicatos do chão da fábrica e a fragilização de seu papel de representação coletiva dos trabalhadores (Neves, 1998). Além disso, permanecem os problemas decorrentes da divisão sexual do trabalho, com desigualdades exageradas nas relações de gênero. Também no Brasil, a produção flexível provocou uma intensificação do trabalho, sem que fossem eliminadas as funções repetitivas, o que acarretou um aumento da LER e de outras doenças ocupacionais (Hirata, 1998).

No Brasil, os estudos de caso sobre os impactos das novas tecnologias e formas de organização da produção sobre a saúde e o comportamento dos trabalhadores têm se concentrado no setor secundário, mais especificamente na indústria de transformação. Em 1997, de modo pioneiro, a Confederação Nacional dos Metalúrgicos da CUT se preocupou em realizar uma pesquisa de campo sobre o processo de inovação no segmento automobilístico, seus impactos sobre a política de recursos humanos e a percepção dos trabalhadores a respeito das mudanças no processo de trabalho e das novas exigências decorrentes (Carvalho, 1998). Com exceção do ramo financeiro, para o qual 
também têm sido realizados vários estudos a este respeito, são raros os segmentos do setor serviços que contam com pesquisas de campo.

Por fim, lembre-se que, num contexto de inúmeras arbitrariedades e de dificuldades crescentes para uma parcela majoritária dos trabalhadores em grandes empresas, os críticos têm denunciado inclusive o discurso aparentemente convincente da responsabilidade social empresarial. Em tese, a adoção de práticas mais humanizadas de administração, colocando no centro das atenções da empresa a qualidade de vida das pessoas, deveria ser um compromisso irrevogável (Karkotli e Aragão, 2004). Mas, não é isso que se observa no Brasil.

Feita esta rápida resenha da literatura sobre o tema, podemos esclarecer que a intenção deste artigo é mostrar nuances das interpretações a respeito das conseqüências para os trabalhadores das mudanças que vêm sendo implementadas. Mais especificamente, pretende-se identificar os principais argumentos que têm sido levantados no debate nacional relacionado com os impactos da introdução de inovações tecnológicas e/ou organizacionais sobre o trabalho em grandes empresas. A análise está dividida em mais cinco seções, nas quais são examinadas as seguintes questões: (i) As inovações tecnológicas exigem a adoção de um modelo flexível de organização do trabalho? (ii) O papel do departamento de Recursos Humanos tem se limitado a adaptar os trabalhadores aos novos requisitos da produção? (iii) Há diferenças significativas entre os métodos de gestão do trabalho no setor industrial e no setor serviços? (iv) Quais as principais conseqüências dos novos métodos de gestão do trabalho para os empregados da grande empresa? (v) A nova gestão do trabalho trouxe mudanças que afetam a sociedade como um todo?

O texto se baseia em depoimentos concedidos durante o V Fórum Social Mundial, realizado em Porto Alegre em 2005. Entre as lideranças sindicais e personalidades de destaque no mundo do trabalho brasileiro, presentes no evento, foram entrevistados: João Vaccari Neto (Secretaria de Relações Internacionais da Central Única dos Trabalhadores); Kjeld A. Jakobsen (Presidente do Instituto Observatório Social); Fernando Lopes (Secretaria Geral da Confederação Nacional dos Metalúrgicos); Marino Vani (Confederação Nacional dos Metalúrgicos e Instituto Integrar); Juçara Dutra Vieira (Confederação Nacional do Trabalho em Educação); Gustavo Codas (Comissão Organizadora do V FSM); e Roni Anderson Barbosa (Diretoria da Central Única dos Trabalhadores do Paraná). Também foi entrevistado Mórgan Fleury Batista dos Santos (Gerência da Mundial S.A. no Rio Grande do Sul) para registrar a opinião de um representante de uma grande empresa.

\section{Impactos das inovações tecnológicas sobre a organização do trabalho}

Em primeiro lugar, é oportuno perceber como os responsáveis pela gestão de grandes empresas compreendem as mudanças em curso. De acordo com Mórgan Fleury Batista dos Santos, 
gerente da linha de produtos Mundial em Porto Alegre, a adoção de um modelo flexível de organização do trabalho é uma exigência do novo padrão tecnológico e das novas estratégias de concorrência adotadas nos mercados atuais.

Perguntado sobre o impacto das inovações tecnológicas ocorridas nos últimos 10-15 anos sobre os métodos de organização do trabalho em uma empresa industrial, ele respondeu que é preciso qualificar o processo das mudanças. Segundo suas palavras:

"Este impacto atingiu fortemente dois focos, quais sejam: a) aumento da competitividade e
b) otimização dos recursos humanos. Com a concorrência em alta, as empresas se vêem
cada vez mais obrigadas a investir fortemente em tecnologia para manterem-se
competitivas. Estas tecnologias trouxeram consigo o aprimoramento dos modelos de
gestão, por meio dos quais se buscou maior competitividade. Foi neste período que
surgiram vários processos tais como: dowsizing, reengenharia, qualidade total, six sigma
etc. Por outro lado, tornou-se também importante os funcionários exercerem diversas
tarefas simultâneas. Não basta mais desempenhar a sua atividade técnico-profissional.
Deve-se ao mesmo tempo preocupar-se com fazer bem e de uma única vez. A tenologia
traz consigo a necessidade do aprimoramento e elevação do nível de escolaridade."

Já no entendimento de Kjeld Jakobsen, presidente do Instituto Observatório Social (onde têm sido desenvolvidos estudos em cooperação com sindicatos de trabalhadores e empresas multinacionais) há um amplo consenso de que também no Brasil houve transformações profundas nos métodos de produção e nas formas de gestão do trabalho. Mas, são raros os casos de geração de inovações, uma vez que a maioria das empresas no País acaba importando equipamentos, métodos e soluções desenvolvidos nos países mais avançados economicamente. Para ele, há exemplos (principalmente no setor industrial, mas também no setor serviços) em que foi a introdução de inovações tecnológicas que exigiu a adoção de modelos mais flexíveis de organização do trabalho, assim como há exemplos em que as novas formas de organização do trabalho independem da base tecnológica. "Nesse sentido, deve-se ter em conta que não há determinismo na relação entre tecnologia e trabalho."

Para João Vaccari Neto, da Secretaria de Relações Internacionais da CUT, as mudanças ocorreram em dois momentos: inicialmente, o trabalho foi organizado de uma forma mais racional com o objetivo de elevar a produtividade, utilizando ainda os mesmos meio de produção; depois, principalmente nos últimos dez anos, houve um outro processo, no qual as empresas procuraram incorporar as novas tecnologias. Ele acrescenta:

"Então, são duas coisas que fazem com que haja o crescimento da produção de forma
bastante grande. E, ao mesmo tempo, os salários não acompanham essa evolução. O
número de empregados diminuiu e a produtividade explodiu. Então, se você pegar qualquer
setor da indústria, percebe que houve um crescimento da produtividade nos últimos 20 anos
de forma muito grande. Isso foi um reflexo das inovações."

Segundo o seu ponto de vista, nesse período, duas novidades foram adotadas na maioria das empresas industriais. Uma é a cobrança de metas nas empresas, metas coletivas e individuais: "Qualquer empresa hoje trabalha com esse método de metas.” A outra é a adoção de novos métodos 
de controle e gestão de pessoal, nos quais o próprio trabalhador passa a colaborar para prevenir problemas.

\begin{abstract}
"A empresa tem que produzir X e o funcionário tem que produzir uma fração de X. A somatória de todos vai fazer com que o valor do X cresça, vá lá em cima. Então, nós temos dois tipos de metas: uma é o objetivo da empresa e a outra meta é estabelecida individualmente. Ao mesmo tempo, as empresas buscam construir formas de controle coletivo sobre a produção. Desse modo, essas metas permitem várias formas de você fazer a gestão de pessoal e o controle produtivo. Vai estabelecendo justamente isso: as metas individuais, coletivas, setoriais vão somando para que no final haja uma explosão da produtividade em todos os setores."
\end{abstract}

Por sua vez, Gustavo Codas, assessor da CUT e um dos responsáveis pela organização do V Fórum Social Mundial, considera que é difícil separar as "inovações tecnológicas" das "inovações organizacionais", uma vez que as empresas buscam combinar inovações nas máquinas, nas matérias primas utilizadas e na organização do trabalho e da produção. Para ele, do ponto de vista do trabalho, esses processos refletem a tentativa das empresas de encontrar formas mais sofisticadas de subordinar os trabalhadores à lógica da acumulação e aos seus interesses imediatos:

"Pode-se ler o acontecido nos anos 90 como uma 'disputa ideológica' do capital com o
trabalho, na qual o capital tomou importantes iniciativas no plano dos métodos de
organização do trabalho, ajudado muitas vezes pelas novas possibilidades oferecidas pelos
novos equipamentos (mas não somente). A minha percepção é de que, na mencionada
disputa ideológica, o capital em muitos casos redesenhou a organização do trabalho. Digo
em muitos casos porque em outros (talvez a maioria), apenas intensificou o modelo
anterior."

Das várias diretrizes que norteiam os novos métodos de organização do trabalho, Codas cita duas. Primeiro: a apropriação do saber operário. O trabalhador não é um "gorila amestrado" (Taylor); acumulou saber e é preciso aproveitá-lo, extrair esse conhecimento para seu uso pela empresa. Segundo: o trabalho em equipe e polivalente elimina "tempos mortos" (e corta postos de trabalho), aumentando a produtividade. Assim, supera-se a segmentação e fragmentação do trabalho, que reduzem a produtividade porque implicam em tempos mortos para a produção, e evita-se a malandragem operária, que tenta sempre ampliar os tempos mortos. Nas suas palavras:

“O trabalhador é 'recompensado' com uma maior qualificação e enriquecimento do seu trabalho, ao mesmo tempo em que é induzido a um trabalho mais intenso e à competição com outros trabalhadores, minando o sentido de solidariedade da classe trabalhadora que o modelo anterior suscitava."

A explicação e a possibilidade de sucesso dessa estratégia estão dadas pelo condicionamento macroeconômico, em particular porque os anos 90 foram marcados pelo grande aumento da taxa de desemprego. O raciocínio é bastante contundente:

"O desemprego sempre foi considerado pelo pensamento político e econômico conservador como um método disciplinador da mão-de-obra. Até que a taxa de desemprego baixe sensivelmente, não há como saber quanto é disciplina imposta e quanto é 'colaboração' ou adesão ideológica do trabalhador ao capital. Mas, podemos afirmar que foi essa alta do desemprego que permitiu um recrudescimento do taylorismo em alguns setores (notadamente nos setores de serviços)." 
Por último, Gustavo Codas lembra que a situação dentro das empresas que produzem bens importáveis se alterou de forma importante com a mudança do regime cambial em janeiro de 1999. Ele explica:

"Até então, a 'âncora cambial' operava como um argumento muito concreto contra as
reivindicações dos trabalhadores, já que fixava um 'teto' para os custos de produção, que se
ultrapassado levaria ao fechamento da empresa. Com a liberalização do câmbio e sua
desvalorização competitiva, houve grande alívio nos locais de trabalho. Antes, cada
mudança organizacional contabilizava algum pequeno percentual de ganho de
produtividade e competitividade. Agora, a desvalorização cambial resolvia os problemas..."

No Paraná, essas tendências também se manifestaram. Roni Anderson Barbosa, presidente da CUT-PR, argumenta que a inovação tecnológica afetou de várias formas o mundo do trabalho. A informatização e a automação mudaram o ambiente de trabalho. Com isso, a organização interna do trabalho também mudou. Mas, na maioria dos casos, as novas tecnologias foram introduzidas sem destruir as antigas plantas industriais. Conforme ele mesmo explica:

\begin{abstract}
"O que a gente vê no Brasil é que a maior parte das indústrias não construiu parques fabris novos, elas foram adaptando os parques fabris antigos para as novas tecnologias e, com isso, foi preciso o trabalhador se desdobrar. Um equipamento antigo com uma tecnologia nova. Isso é o que eu vejo que aconteceu desde a década de 1990 para cá. (...) Com a tecnologia nova, a maioria fez adaptações e isso ocasionou diversas adaptações para o mundo do trabalho, como a redução dos trabalhadores, que foi muito forte. Houve redução de trabalhadores em vários postos de trabalho em razão disso. E com isso veio à reestruturação, reestruturação que não é só uma questão tecnológica."
\end{abstract}

De acordo com ele, a prevalência da política neoliberal fez o Estado brasileiro abrir mão de políticas industriais e isso trouxe conseqüências que prejudicaram muito fortemente o trabalho, num contexto de reestruturação produtiva e de adoção de uma série de programas, como a qualidade total, que também ajudaram na redução de pessoal e na reorganização do trabalho. Portanto, no entendimento de Roni Anderson Barbosa, a gestão de pessoas foi uma das áreas afetadas pelas mudanças ocorridas:

"A gente vê que algumas coisas estão surgindo no mundo do trabalho, pelo lado das empresas, que antes nós não víamos. Tem mudado a gestão de recursos humanos. Elas fizeram, quase todas as empresas fizeram readaptações da década de 1990 em função da tecnologia e da concorrência externa."

\title{
3. O papel do Departamento de Recursos Humanos
}

A questão a ser examinada, nessa seção, diz respeito ao papel que tem sido atribuído, nas grandes empresas, ao Departamento de Recursos Humanos. E, nesse sentido, verificar o que tem sido feito para adaptar os trabalhadores aos novos requisitos associados ao capitalismo desregulado, à difusão da inovação tecnológica e às pressões derivadas da competição globalizada.

Para Mórgan Fleury Batista dos Santos, o departamento responsável pela gestão dos chamados "Recursos Humanos" também foi impactado fortemente pelas mudanças no funcionamento das empresas. De fato, o papel desse departamento foi expandido: 
“O antigo Departamento Pessoal deu lugar ao Departamento de Recursos Humanos, que pode ainda assumir diversas nomenclaturas, tais como: Talentos Humanos, Inteligência Humana, Área de Emoções etc. Também houve uma mudança na postura: o RH paternalista deu lugar a um RH que deve ser focado em resultados, buscando formas de auxiliar a empresa a atingir seus resultados. Novos programas de desenvolvimento e formas de remuneração por resultados vieram em conjunto. O profissional de $\mathrm{RH}$ deve agora aprender a linguagem do negócio. A formação financeira passa a acompanhar o dia-a dia destes profissionais."

Por outro lado, Marino Vani, com base na experiência acumulada como coordenador de formação sindical dos trabalhadores metalúrgicos, enfatiza a estratégia agressiva adotada pelas empresas brasileiras, através dos responsáveis pelas políticas de RH, buscando ganhar a confiança e a cooperação dos trabalhadores para o melhor desempenho possível no mercado. Nas suas palavras:

\begin{abstract}
“A grande maioria das empresas trabalha com uma política de aproximação e de convencimento de que o sucesso da empresa depende dos trabalhadores e os trabalhadores dependem da empresa. Essa política de colocar os trabalhadores como co-responsáveis por todo desempenho, pelos resultados da empresa, é uma política muito agressiva, na qual os trabalhadores se tornam mais responsáveis do que o próprio dono da empresa. E sofrem com estresse, sofrem muito com a pressão, $\mathrm{E}$ buscam cumprir as metas se responsabilizando pelos resultados finais da empresa. Mas, na grande maioria dos casos, as metas colocadas através de programas de PLR - participação dos lucros e resultados, de programas que envolvem os trabalhadores para atingir o que foi estabelecido pela empresa, são metas quase sempre impossíveis de serem alcançadas."
\end{abstract}

O envolvimento dos funcionários na gestão da produção acaba fazendo que o ritmo da produção (e do trabalho) seja aumentado pelos próprios trabalhadores, muitas vezes sem a necessidade da direção da empresa emitir uma ordem. Ou seja, os próprios trabalhadores, através dos novos processos de organização do trabalho, vão se auto-organizando e buscando alternativas para garantir a satisfação das metas.

Marino Vani explica que muitos departamentos de RH acabaram assumindo, nesse período de transição, de mudanças no processo produtivo e no foco da empresa, o papel de administrar também o trabalho realizado em outras pequenas empresas ou por outros grupos de trabalhadores, que aparecem como cooperativas. O RH acaba tendo a função de fazer a gestão junto a outras empresas ou grupos que trabalham de forma subordinada a um mesmo processo produtivo. Segundo Vani:

“Então, o RH passou a ser um administrador de contratos onde a empresa negocia o fornecimento de serviços de assistência técnica, de montagem, que a empresa deixou de fazer nos últimos tempos. Em alguns casos, quando o sindicato tem uma relação mais forte, os RH das empresas acabam sendo acionados para resolver algum problema de conflitos trabalhistas no âmbito de empresas terceirizadas (ou mesmo de cooperativas). Então, o RH tenta administrar esses conflitos. O problema é que essa estratégia do RH de tentar terceirizar o máximo possível da produção acabam fazendo com que os trabalhadores tenham dentro da mesma empresa (ou processo produtivo) relações e condições diferenciadas. Os trabalhadores terceirizados têm salários e benefícios, na maioria das vezes, $50 \%$ menores do que outros trabalhadores similares. E a grande maioria já trabalhou na própria empresa, mas agora são funcionários de uma pequena empresa que o chefe ou o líder daquele setor criou (ou o presidente da cooperativa é um ex-chefe de um determinado setor)."

Além de administrar conflitos da relação capital-trabalho, a nova política de RH deve contribuir para que as empresas diminuam os seus custos. Além de cuidar da seleção, contratação, 
pagamento e treinamento dos funcionários, o departamento de RH agora precisa cuidar de contratos comerciais, com os quais a empresa pode ganhar mais ou menos dependendo do desempenho dos trabalhadores terceirizados (ou cooperados). A maior parte dos custos da empresa deve ser variável (conforme varia a produção). Reduzir a folha de pagamentos (custo fixo) e recorrer a trabalhadores subcontratados podem até não ser medidas muito mais rentáveis, mas se torna uma estratégia cada vez mais comum à medida que os concorrentes passam a adotá-la. Para concluir o raciocínio, Marino Vani acrescenta:

“O RH mudou as funções, assumiu novas funções e hoje desempenha um papel mais importante que no passado. É um papel que vai além das relações com os trabalhadores e com os sindicatos. Ele agora tem uma relação com outras empresas, outros setores, ele contrata a mão-de-obra de um outro parceiro e de outra empresa. E isto faz com que os responsáveis pelo RH tenham que ter uma formação muito maior: têm que estar preparados para negociações com outros empresários, além dos sindicatos, é claro. Mas, esses contatos têm que estar muito bem estabelecidos, porque a Justiça do Trabalho, muitas vezes, considera isso como um vínculo empregatício. E futuramente virão conseqüências, pode acarretar custos maiores para a empresa. Então, hoje, o RH tem uma assessoria jurídica muito grande, uma assessoria que não existia no setor de RH. Claro que isso não é em todas as empresas. Mas vejo isso no ramo de bens de capital, na indústria de máquinas, nas empresa que fazem montagem de eletro-eletrônicos, no setor automobilístico. Enfim, o RH é um coordenador de mão-de-obra da própria empresa e de outras que trabalham articuladas no mesmo processo. Por isso, a responsabilidade do Departamento de RH é muito maior em relação ao passado."

Por sua vez, Fernando Lopes, secretário geral da CNM, enfoca a questão da política de Recursos Humanos das empresas brasileiras de outro ponto de vista: as razões do sucesso das estratégias implementadas. Ele é bastante claro em sua argumentação:

“Avaliamos que a política de RH tem sido vitoriosa na sua implantação, do ponto de vista
dos objetivos empresariais. E isso é possível por conta de três motivos:
$1^{\circ}$ ) Essas políticas evocam um discurso democrático, participativo. Na realidade, elas são
implementadas num ambiente profundamente antidemocrático. O trabalhador não tem
opção entre aceitar ou não essas políticas participativas, o controle de qualidade e todos
esses métodos japoneses. Então, isso é um fator importante para o sucesso da empresa. Na
realidade, é uma política de costumes democráticos, mas tem um método de implementação
autoritário. Até porque, no Brasil, existe a questão do desemprego... E num país sem
emprego o trabalhador não pensa duas vezes em acatar ou não acatar uma determinação da
empresa. Esse é um fator importante.
$2^{\circ}$ ) Os trabalhadores são críticos dos antigos métodos de trabalho. Ou seja, quem trabalha
num ambiente com supervisor, com hierarquia bastante rígida dentro da empresa, é
favorável à mudança. Se existe um ambiente onde, minimamente, mesmo de forma
limitada, você tem condições de participar das decisões, torna-se uma coisa atrativa pelo
lado dos trabalhadores. Portanto, essas políticas oferecem algo que vai ao encontro dos
desejos de todos, que é trabalhar num ambiente onde não há necessariamente um chefe que
mande neles. Essas políticas seduzem os trabalhadores.
$3^{\circ}$ ) Outro fator de sucesso dessas políticas é a incapacidade dos sindicatos de dialogar com
isso e enfrentar essas políticas de forma dignamente competente. Raramente os sindicatos
se opõem à implementação dessas políticas na empresa. Mas, por conta de não estarem
presentes no local de trabalho, não conhecerem diretamente como funciona a fábrica.
Acabam fazendo um discurso fora do portão da fábrica, diferente dos trabalhadores. Até
porque os funcionários são novos trabalhadores, são estudantes saídos de escolas técnicas.
Então, o discurso sindical não consegue ganhar os trabalhadores para fazer o enfrentamento
conseqüente da política das empresas. Esses são os três fatores que contribuem para que
essas políticas sejam implementadas.”

Em suma, essa política empresarial parece ter sido bem sucedida, no Brasil. Nessa política, um aspecto se destaca: tem sido muito difundido o discurso do trabalhador como parceiro, 
colaborador. Inclusive, muitos sindicatos atualmente assumem essa estratégia de atuar como parceiro da empresa. Para João Vaccari Neto, porém, esse discurso é apenas mais uma forma de tentar mascarar o conflito inerente à relação capital-trabalho.

"Eu não acredito que o trabalhador seja parceiro porque, no meu entendimento, parceiro é
quando a sua opinião é aceita, você compartilha da opinião. Aí sim podemos dizer 'somos
parceiros, vamos discutir coisas juntos'. Mas não é assim. As metas, muito provavelmente
são estabelecidas por alguém que não te conhece, não freqüenta o seu local de trabalho, não
sabe como é, mas tem um objetivo financeiro - o resultado econômico que ele deseja
atingir. E a partir daí fixa uma meta e não permite questionamento. (...) Eu acho importante
dizer isso, porque é preciso ter claro que a relação capital-trabalho deve ser uma relação
regrada, com critérios, com princípios, feitos entre os verdadeiros representantes: o
sindicato de um lado e os empresários do outro. (...) Uma relação de parceria entre o
trabalhador e a empresa teria que ter uma natureza voluntária. Por isso, já coloco de
antemão que 'colaboração' não é o que ocorre com o trabalhador que está na produção, no
escritório, numa empresa de serviço, num navio, num avião. Isso não acontece. (...) Então,
essa história de parceiro é uma tentativa de mascarar a relação capital-trabalho. Acho que é
muito melhor a gente tratar de forma mais transparente, com objetivos para discutir com
todos os envolvidos."

Em resumo, para Vaccari, como os Departamentos de Recursos Humanos têm procurado se adaptar a uma nova realidade, hoje também as negociações entre os representantes dos patrões e dos trabalhadores também têm sido afetadas. Os sindicatos estão procurando se adaptar a esse novo ambiente de negociações, porém, com os velhos argumentos. Por outro lado, hoje há mais consultores trabalhando para resolver os conflitos trabalhistas nas empresas, mas os problemas continuam tão graves como antigamente.

Por sua vez, Roni Anderson Barbosa acredita que, no Paraná, os gestores das empresas, inclusive nos Departamentos de RH, não estão preocupados com estimular os empregados a melhorar o produto ou aumentar o ritmo de produção. Para ele, predominam as tentativas de reduzir os custos de produção. Em suas palavras:

"Acho que são pouquíssimas as empresa que se preocupam com esse lado de estimular o
trabalhador, porque o que a gente fala muita vezes é que, se o trabalhador no geral tivesse
meio de se organizar, de se ajudar, de se reunir no próprio local de trabalho para remodelar
o processo produtivo, certamente isso beneficiaria. O trabalhador pode ter uma certa
autonomia para decidir algumas coisas, ser ouvido. Ajudaria até para a própria empresa,
porque o trabalhador se sentiria valorizado enquanto participante dessa mudança.
Certamente, isso beneficiaria a empresa na melhoria da produção."

De qualquer forma, Barbosa acrescenta que houve uma reestruturação no quadro dos empregados e na política de $\mathrm{RH}$, à medida que novas relações de produção e trabalho foram construídas a partir da eliminação de alguns cargos na hierarquia das grandes empresas. Em nome da qualidade dos produtos e serviços prestados, as empresas paranaenses passaram a adquirir inovações tecnológicas, a exigir um novo perfil de trabalhador e a adotar novos critérios de gestão do pessoal. No novo discurso adotado, a troca de conhecimentos e a sistematização de experiências foram valorizadas. Nesse sentido, ele concorda que houve alguns resultados positivos:

"Há pouco, eu falei da questão da organização no local de trabalho, que é muito restringida. Tem algumas empresas que atuaram nesse sentido de eliminar níveis hierárquicos, constituíram grupos nos locais de trabalho e em determinados setores deram maior autonomia a esses trabalhadores. E eles tiveram resultados em aumentar a produtividade. 
Houve melhoria numa série de questões, como o clima organizacional na empresa. Toda vez que você dá certa autonomia ao trabalhador, não só para fazer aquilo que ele foi contratado, surgem oportunidades de participar das decisões da empresa. Isso melhora o clima e conseqüentemente a produtividade. E certamente melhora o ambiente de trabalho como um todo."

\section{Diferenças entre o setor industrial e o setor de serviços}

É sabido que, ao longo da década de 1990, o Brasil passou por um intenso processo de mudanças econômicas e políticas, marcado principalmente pela criação do Plano Real, pela abertura da economia e pela privatização de empresas estatais. As empresas ficaram expostas a uma brutal concorrência externa e, para sobreviverem e se manterem competitivas no mercado, tiveram que adotar novas tecnologias e novas formas de organização do trabalho e da produção. Mas, esse novo cenário teve impactos distintos sobre as empresas da indústria de transformação e da construção civil, de um lado, e as empresas do setor de serviços e do comércio, de outro. Por isso, alguns dos entrevistados se manifestaram sobre a seguinte pergunta: Há diferenças significativas entre o setor industrial e os serviços, no que se refere aos métodos de gestão do trabalho em grandes empresas?

Para Mórgan Fleury Batista dos Santos, não existem grandes diferenças nos métodos de gestão dos departamentos de Recursos Humanos, pois em ambos os setores as empresas têm que procurar melhorar sua eficiência para atingir os resultados predeterminados. Ele acredita que as novas tecnologias de gestão aplicam-se a qualquer tipo de empresa de grande porte. E ele acrescenta que, em ambos os setores, o importante é procurar satisfazer o cliente e os acionistas.

Já Gustavo Codas acredita que há uma diferença perceptível: “Aparentemente, os métodos 'tayloristas', hoje, são mais presentes no setor de serviços, enquanto no setor industrial se aplicam mais os novos métodos de gestão.” De qualquer forma, no seu entendimento, tanto na indústria como nos serviços, os Departamentos de Recursos Humanos tiveram, nesse período, de redefinir o tipo de trabalhador(a) requerido pelas novas tecnologias e métodos de organização do trabalho (critérios como escolaridade, participação, espírito de trabalho em grupo etc.), assim como tiveram de desenvolver mecanismos para estimular os funcionários, em especial por meio de recompensas (surgem novas formas de remuneração ligadas ao desempenho da empresa ou do setor ou do grupo de trabalho).

De acordo com Juçara Dutra Vieira, da Confederação Nacional do Trabalho em Educação, há ramos de atividade no setor de serviços que estão muito distantes das transformações mencionadas anteriormente, ou seja, que não apresentam as mesmas tendências. É o caso da educação pública. Por outro lado, na área da saúde pública, mesmo considerando as precariedades da rede hospitalar e a falta de acesso ao atendimento básico em algumas regiões, pode-se perceber que houve incorporação de novas tecnologias. "Hoje, se você for fazer um exame simples, você 
conta com um aparato tecnológico bastante sofisticado." Portanto, no campo do funcionalismo público, de um modo geral, existe uma grande diferenciação em termos de processo de trabalho, de tamanho dos estabelecimentos e de gestão de Recursos Humanos.

De qualquer modo, o exemplo da educação (pública ou privada), em particular no ensino fundamental, demonstra que há diferenças importantes em termos de adoção de novas estratégias organizacionais para adaptação ao novo contexto econômico. Ela mesma explica que há muito que avançar nessa direção:

"Na área da educação, estamos defasados uns dois séculos, mais ou menos. As escolas
ainda não incorporaram a tecnologia. E, naqueles setores que incorporaram, foi para retirar
da população o direito à inclusão ou à qualidade no ensino. Por exemplo, a educação à
distância, que poderia ser um instrumento de inclusão. Da forma como tem sido feita, retira
a possibilidade de educação presencial de qualidade e terceiriza esse tipo de serviço. Então,
no setor público a gente infere que haja essas grandes contradições. É evidente que nós
queremos que a evolução tecnológica, científica, o avanço das comunicações, possam
chegar para os trabalhadores. Mas o modo como tem chegado... o impacto que tem gerado
não é um impacto positivo para os trabalhadores."

Por fim, Roni Anderson Barbosa lembra que há diferenças entre alguns setores econômicos com relação às formas de contratação. Por exemplo, comparando trabalhadores da indústria com os comerciários. Em suas palavras:

\begin{abstract}
“Tem sindicatos lá no sudoeste do Paraná que atendem estudantes que foram contratados pelas empresas como estagiários de história para cuidar de almoxarifado, estagiários de enfermagem para vender produtos etc. Alguns institutos e instrumentos legais foram deturpados para burlar a legislação trabalhista, ou seja, para você não ter o registro em carteira e não caracterizar o vínculo empregatício. A informalidade ainda é muito grande no comércio e as empresas buscam ainda mais redução de custos, atacando o direito do trabalhador, coisa que nós não admitimos em hipótese alguma."
\end{abstract}

Portanto, é claro que a gestão do departamento de RH pode variar muito conforme o setor de atividade e o tamanho da empresa, ou mesmo a existência de fiscalização governamental. As divergências de opinião a respeito deste tópico, registradas nos depoimentos, devem-se aos diferentes enfoques que cada entrevistado deu à questão.

\title{
5. Conseqüências dos novos métodos de gestão para os empregados
}

O conjunto de mudanças aqui relatadas tem diferentes significados para os diversos atores sociais. Mas, um dos consensos é que esse processo de reestruturação empresarial tem causado impactos na vida dos trabalhadores, para os sindicatos, para a sociedade em geral e mesmo para o meio ambiente. A seguir, é apresentada a opinião dos entrevistados a respeito das principais conseqüências dos novos métodos de gestão do trabalho para os empregados da grande empresa.

Mórgan Fleury Batista dos Santos destaca que aumentou, significativamente, a pressão exercida sobre o trabalhador na busca por resultados. Cada vez menos "colaboradores" devem se responsabilizar por mais tarefas, o que se traduz em aumento de produtividade. Olhando 
especificamente a situação dos trabalhadores com nível superior, ele atesta que o mercado de trabalho está restringido, fazendo com que profissionais qualificados submetam-se a condições de trabalho bem menos qualificadas. E mesmo nesse nicho, a informalidade está aumentando; por conseqüência a formalização do emprego diminui entre os graduados. Daí, ele projeta: “O trabalhador do futuro deverá ser o gerente de sua carreira."

Para ele, os departamentos de RH têm estimulado os funcionários a buscar melhorar o currículo, inclusive oferecendo cursos in company, que passaram a fazer parte do dia-a-dia das grandes empresas. Mas, o autodesenvolvimento passou a ser a palavra de ordem. Como tendência, ele visualiza:

\footnotetext{
"As carreiras autogerenciáveis, em que os profissionais passam de uma atitude passiva (as empresas investiam em cursos) para uma postura pró-ativa (o trabalhador passa a investir na sua empregabilidade)."
}

Em contrapartida, Kjeld Jakobsen relata que a busca da competitividade virou uma obsessão que, somada aos novos modelos de gestão implantados pelas grandes empresas, contribuiu não só para o aumento no número de desempregados e para a proliferação de precárias condições de trabalho; também contribuiu para exacerbar o individualismo dos trabalhadores. Conforme aumenta a concorrência entre eles, diminui a capacidade de mobilização coletiva. Os sindicatos de trabalhadores viram o seu poder de barganha diminuir, assim como o número de sindicalizados.

Por sua vez, João Vaccari Neto procura estabelecer uma avaliação que reconhece aspectos positivos e aspectos negativos, no que se refere ao impacto dos novos métodos de organização do trabalho. Mas destaca os aspectos negativos, argumentando assim:

"É importante dizer que há ganhos do ponto de vista das condições de trabalho e há ganhos
do pontos de vista do ambiente de trabalho. Mas, em contrapartida, há uma pressão
psicológica, uma pressão bastante grande sobre o trabalhador. Por exemplo, quando circula
um carro numa linha de produção, ele circula mais ou menos com os tempos contados de
entrada e saída. E os trabalhadores têm que competir com a esteira, o tempo todo ele
compete com a esteira. E para vencer vai sendo adequado na justa medida da sua
velocidade. Quanto mais rápido o trabalhador executar a tarefa, mais rápido a esteira vai
andar."

Vaccari diz que há uma constante na implantação de novas tecnologias. Primeiro, surge o debate sobre os ganhos e prejuízos, uma projeção das perdas e avanços. Em seguida, vem um determinado espaço de adaptação, de aceitação das novas tecnologias. Depois, vem uma reação, quando os trabalhadores começam a sentir que a situação não ficou melhor, mas piorou. E os sindicatos melhor organizados procuram fazer uma nova política de enfrentamento.

Outro aspecto destacado por Vaccari é a intensificação do trabalho e o uso de mão-de-obra de terceiros. Isso também, num primeiro momento, é visto como uma coisa boa (no caso de funcionários que passam a prestar serviços para a empresa), mas depois os trabalhadores vão se conscientizando de que seus problemas não foram resolvidos. A terceirização muitas vezes é defendida como uma maneira de dar mais autonomia aos funcionários, de melhorar a vida dos 
trabalhadores, mas acaba aumentando a exploração do trabalho, aumentando os ganhos das empresas. Para ele:

"O fundamental é dizer que os ganhos tecnológicos, nesse último período, não estão sendo incorporados ao patrimônio dos trabalhadores, seja nos salários, seja nos direitos, seja na qualidade de vida ou na convivência social."

Por último, Vaccari contribui relatando como as mudanças interferiram nas relações interpessoais dos trabalhadores:

\begin{abstract}
"As mudanças interferiram nas relações dos trabalhadores na medida em que você passa a ter uma competitividade bastante grande e aqueles que não correspondem são eliminados. Quem trabalha mais devagar, a tendência é o coletivo excluir. Isso ocorre muito com as mulheres, porque elas ficam grávidas, rendem menos, isso é normal. Então, não é o patrão que vai excluir o sujeito, são os próprios colegas. Essa é uma grande 'sacanagem', porque eles não vêem o ponto de vista do colega, vêem o ponto de vista da produção. Tem empresa em que o funcionário adquire uma doença e isso cria uma segregação."
\end{abstract}

Por sua vez, Marino Vani ressalta que é impressionante como aumentaram as queixas de problemas emocionais, psicológicos, de estresse, depressão. Aparentemente, quanto mais moderna é a empresa, mais doenças relacionadas ao trabalho são diagnosticadas. Ele explica:

"A empresa moderna traz mais esse tipo de doenças profissionais. Uma, porque o ritmo de
trabalho é muito grande. Temos empresas automobilísticas com 1.500 trabalhadores na
planta e, desses, em torno de 500 trabalhadores já fizeram ficha de acidente de trabalho
ficando mais de 15 dias afastados por problemas que antes não existiam (a LER, por
exemplo). Isso porque as empresas não têm uma política de trocar os trabalhadores de
setores e também por motivos relacionados ao estresse. Quase $1 / 3$ dos trabalhadores das
empresas montadoras tem ou está tendo problemas com doenças profissionais graves, que
acabam fazendo lesões e levam os trabalhadores a, futuramente, estar fora de qualquer
possibilidade de trabalho. E isso vem aumentando principalmente nas grandes empresas e
nas empresas mais modernas."

Outra conseqüência apontada por Marino Vani, com a redução no número de trabalhadores da categoria, é o baixo grau de sindicalização. Além disso, as novas políticas empresariais dificultam ainda mais a organização autônoma dos trabalhadores e sua representação coletiva. Segundo ele:

"Nosso sindicato tem certa dificuldade de identificar quem são os contratados pela empresa-mãe e quais são os das terceirizadas, das cooperativas. Com isso, nas mobilizações que fazemos agora, dentro ou fora da fábrica, para a campanha salarial ou para qualquer campanha que o sindicato desenvolva, há uma participação menor; e é cada dia maior o medo dos trabalhadores em perder o emprego na empresa-mãe (e ser terceirizado). Ou seja, aumenta também o estresse diário dos trabalhadores."

Também no entendimento de Fernando Lopes, as conseqüências dos novos métodos de organização dos trabalhadores são claramente prejudiciais:

“A minha avaliação é que as conseqüências dessas políticas são ruins para os trabalhadores. Em médio prazo, existe uma perda da autonomia no trabalho que, aparentemente, no começo não é evidente. Existe uma sobrecarga do trabalho. Existe um aumento do ritmo do trabalho. E existe um prejuízo na relação do trabalhador com a entidade sindical. É um processo gradativo. Mas os resultados negativos não têm sido revertidos. Poucas experiências de política sindical, no Brasil, foram capazes de ser inovadoras para enfrentar essa situação."

Para Gustavo Codas, o contexto em que vêm sendo aplicados os novos métodos de gestão do trabalho tem sofrido importantes mudanças ao longo dos últimos 15 anos. Isso dificulta tirar 
conclusões. Talvez as tendências atuais sejam diferentes daquelas percebidas na década passada. De qualquer modo, ele sugere que o impacto principal foi uma maior desigualdade no interior dos empregados ligados aos seguimentos mais dinâmicos da economia brasileira, fazendo a seguinte avaliação:

\begin{abstract}
“Antes de janeiro de 1999, diria que as principais tendências eram: a) diminuição do número de trabalhadores diretos nas empresas e melhora da remuneração deles em relação ao crescente número de terceirizados (e, em alguns casos, em relação a sua situação anterior); b) aumento da qualificação dos trabalhadores diretos; c) aumento do ritmo de trabalho, tanto dos funcionários diretos como dos terceirizados; e d) diminuição do poder de pressão pelo aumento do grau de diferenciação entre trabalhadores."
\end{abstract}

Por fim, em relação ao contexto paranaense, Roni Anderson Barbosa confirma que os novos métodos de gestão contribuíram para o aumento de doenças profissionais nas grandes empresas. Nas suas palavras:

"Por exemplo, se pegarmos a categoria dos bancários: com o aumento da tecnologia e o uso de computadores, os acessos são todos informatizados, as compensações bancárias que antes demoravam horas e horas, hoje você tem a informática para ajudar. Mas, os bancários continuam tendo problemas de lesões por esforço repetitivo, porque a mudança na organização do trabalho não diminuiu o ritmo do trabalho, a uma série de outros fatores. Eu vejo que isso está conectado. Os acidentes de trabalho, as doenças ocupacionais têm continuado a crescer e a se desenvolver. A doença mais freqüente é a LER, não só na categoria dos bancários, em outras categorias também."

Ele aponta, ainda, o crescimento de problemas psicológicos decorrentes do estresse emocional a que são submetidos os trabalhadores nos tempos atuais:

"Tem problemas relacionados ao estresse, que decorrem da forte pressão psicológica sobre
os trabalhadores para aumentar a produção, a produtividade, a qualidade. A gente sabe de
muitas indústrias por aí em que o número de trabalhadores que está com dependência
química, tomando remédios para tratamento de depressão, com problemas de saúde em
geral e problemas psicológicos sérios. Até casos de trabalhadores que se matam no local de
trabalho. Isso não é de agora, não é da década de 1990 para cá, já existia, mas não era tão
visível. Acho que isso acirrou muito nos últimos anos, cresceu bastante esse tipo de doença
relativa à saúde mental do trabalhador, vamos dizer assim."

Além disso, Roni Barbosa diz que também vem aumentando o registro de queixas de assédio moral, ou seja, problemas decorrentes do abuso de autoridade, humilhação dos funcionários, desvalorização do ser humano. Ele explica:

"O assédio moral que a gente fala vem crescendo bastante nas empresas e isso contribui para o aumento dessas doenças psicológicas. O que contribui para o aumento desse assédio moral é o aspecto da competição no mercado [de trabalho] aberto, as novas exigências feitas aos trabalhadores."

Perguntado sobre as mudanças que se verificaram na vida dos trabalhadores, Roni Barbosa diz que o impacto principal foi o afastamento dos vínculos afetivos que existiam dentro daquele grupo de pessoas.

“Antes você tinha um bom relacionamento no local de trabalho. Em geral, via os trabalhadores no seu local de trabalho mais unidos, participando de churrascos, futebol, de esportes juntos. Isso diminuiu bastante de um período para cá. Eu acho que essa inovação tecnológica, aliada à pressão interna por produção, mais o assédio moral, todas essa questões levaram ao que a gente chama de individualismo. Os trabalhadores se fecharam no mundo deles, diminuindo o sentimento de coletividade. Porque, em muitas empresas, o que predomina é o discurso individualista, que certamente influenciou nessa relação interpessoal no local de trabalho." 
Em suma, no Paraná, de acordo com Roni Barbosa, aquelas inovações não vieram para benefício do trabalhador - pelo menos, esse é o sentimento que predomina entre os trabalhadores. A exploração do capital sobre o trabalho, diz ele, continuou nesse período, mesmo com as inovações tecnológicas. Mas ele acrescenta:

\footnotetext{
"Não quer dizer que eu sou contra as inovações tecnológicas, pelo contrário. Eu acho que é um fator importante, que vem ajudar no mundo do trabalho. Mas, é preciso repartir isso com o trabalhador. Quem está ganhando, até agora, são os donos dos meios de produção, os capitalistas. Tanto é que uma das principais reivindicações da CUT, nesse período agora, é a redução da jornada de trabalho, porque tem espaço no Brasil para reduzir a jornada de trabalho. Então, esse seria um dos mecanismos de repartir com os trabalhadores os ganhos de produtividade que a tecnologia trouxe."
}

\section{Conseqüências das mudanças para a sociedade como um todo}

Certamente, as mudanças mencionadas estão presentes na produção, no comércio, no consumo, na tecnologia, na informação, na maioria dos segmentos da atividade econômica, influenciando na criação de novos hábitos e diferentes visões de mundo. A conseqüência imediata dessa nova realidade vem sendo percebida através de manifestações concretas em que se alteram os papéis de pessoas, empresas e até mesmo das instituições governamentais.

Nesta seção final, são apresentados os depoimentos dos entrevistados com relação às conseqüências dos novos métodos de gestão do trabalho que extrapolam o universo das relações de trabalho, envolvendo outras dimensões da sociedade brasileira.

Mórgan Fleury Batista dos Santos acredita que as novas políticas empresariais e os novos métodos de gestão do trabalho não só influenciam a vida dos trabalhadores como trazem mudanças para a sociedade. Para ele, a principal conseqüência é a mudança de atitude, no comportamento das pessoas, que querem ser bem atendidas e atuar de forma mais eficiente e econômica. Para ele, as pessoas introjetam os princípios ditados pela empresa bem-sucedida. Nas suas palavras:

\footnotetext{
"O trabalhador reproduz em casa o modelo de organização do trabalho da empresa. A sociedade vive a expectativa de uma prestação de serviços rápida. O consumidor não aceita
} a baixa qualidade."

Apontando em outra direção, Gustavo Codas enfatiza a íntima relação entre a organização empresarial e a organização social, sugerindo que há o projeto de reestruturação produtiva está em acordo com o projeto neoliberal de reordenamento da economia e da sociedade nos países industrializados e no Brasil. Ele explica:

\footnotetext{
“Assim como o 'fordismo' foi visto (pelo Gramsci) não somente como uma forma de organizar a fábrica, mas também a sociedade, estes novos métodos estão inseridos na lógica do combate que o capital trava, através do neoliberalismo, contra as conquistas da classe trabalhadora desde inícios dos anos 1980. Trata-se de remodelar a empresa e a sociedade, ao mesmo tempo. Uma só pode acontecer junto com a outra. E a crise do projeto de sociedade (o neoliberalismo) ainda deve ser estudada de que maneira está refletindo dentro da organização do trabalho."
} 
Por sua vez, Juçara Dutra Vieira diz que, nos últimos anos, o processo científíco e tecnológico reconfigurou as relações de trabalho, mas especialmente pela influência das empresas de tecnologia de ponta, das empresas que necessitavam de trabalho especializado. Ao mesmo tempo, verificou-se um grande segmento dos trabalhadores indo para a informalidade, abrangendo um número maior de áreas da atividade humana e marginalizando grandes contingentes da população. Portanto, ela ressalta o processo de exclusão social associado à modernização tecnológica:

"O progresso técnico não tem servido para inclusão e nem para melhorar as relações de trabalho. Por outro lado, também se percebe que há nesse setor mais informal uma variação muito grande, porque tanto há aquelas pessoas que, tendo o seu computador em casa, conseguem trabalhar sozinhas e ter uma boa renda, como temos aqueles que estão à margem de toda essa inovação tecnológica."

Kjeld Jakobsen, por sua vez, lembra que muitas empresas vêm adotando o conceito de Responsabilidade Social Empresarial a fim de legitimar o seu papel na sociedade em geral e diante dos demais segmentos com os quais interagem (clientes, fornecedores, sindicatos, governo, mídia etc.) Porém, as empresas não aceitam dialogar com os sindicatos as ações e os procedimentos relativos ao tema, isto é, recusam-se a discutir o que caracteriza uma atitude socialmente responsável. Em particular, cita o levantamento feito pelo Instituto Observatório Social a respeito de programas implementados por multinacionais no Brasil, afirmando que há ainda muito que avançar, inclusive considerando o universo do empresariado nacional. $O$ debate sobre a responsabilidade social, em suma, coloca para os sindicatos novos desafios, que exigem também deles um reposicionamento quanto às formas de intervenção nos rumos da sociedade brasileira.

Ainda sobre o tema da responsabilidade social das empresas, Marino Vani relata um aspecto negativo de algumas experiências. Segundo ele:

"Na maioria das vezes, os trabalhadores são envolvidos em programas e políticas da
empresa objetivando buscar uma imagem junto à sociedade, nos quais assumem de forma
voluntária uma carga horária, uma jornada extra, legitimando a empresa como socialmente
responsável. Contudo, na grande maioria são programas de caráter populista,
assistencialista, fazendo com que os trabalhadores acabem criando essa visão de que ajudar
e ser solidário com os outros é apenas dar alguma coisa que sobra ou que eles possam tirar
do seu próprio fruto. E a grande maioria das políticas acaba deixando as populações ou os
grupos atendidos através desses programas mais dependentes. E muitas vezes até fazendo
uma propaganda exagerada do que realmente foi feito."

Conforme João Vaccari Neto, a responsabilidade social que as empresas deveriam ter inclui um conjunto de deveres: respeitar as leis, trabalhar bem, tratar bem seus trabalhadores, cuidar do local de trabalho. Elas também deveriam demonstrar uma preocupação com o local de trabalho, com o meio ambiente, com a comunidade. É preciso, portanto, ampliar o significado do conceito. Nas suas palavras:

"Porque não adianta você ter um local de trabalho que paga mal, produz mal, é conivente com acidentes de trabalho, é um gerador de doenças do trabalho, é um construtor de problemas para o entorno, polui o meio ambiente. E você resolve, então, para aliviar sua consciência, fazer doação para o Unicef, porque é uma ação social. Eu acho que 
Responsabilidade Social não é isso. É uma mudança de atitude, é uma mudança de cultura, que tem que atingir o conjunto."

Por fim, este tem sido um tema discutido também no Paraná. De acordo com Roni Anderson Barbosa, se as empresas querem ser socialmente responsáveis, devem começar promovendo condições de trabalho seguras e saudáveis, promovendo a igualdade de oportunidades entre homens e mulheres, recusando qualquer tipo de discriminação no ambiente de trabalho. Assim, estarão contribuindo para construir uma sociedade melhor e mais justa. Ele argumenta da seguinte forma:

\begin{abstract}
"A questão da responsabilidade social das empresas não pode se restringir à visão que algumas empresas têm, que é destinar um recurso para comprar cestas básicas ou para ajudar uma determinada comunidade, um mero assistencialismo. A empresa deve cumprir os compromissos que ela tem com os seus trabalhadores, ou seja, cumprir a legislação trabalhista, cumprir os acordos coletivos, cumprir os contratos. Deve ter regras de conduta, código de ética, que valem para todos. Então, a responsabilidade social, na nossa visão, começa com você fazendo o dever de casa, ou seja, você trata os trabalhadores com dignidade e a partir daí você pode implementar ações que possam ajudar, seja na geração de empregos, seja na qualificação, seja no desenvolvimento da cultura em determinada comunidade ou com outras ações."
\end{abstract}

Certamente, se no mundo do trabalho fossem valorizados certos princípios e atitudes, isso poderia contribuir para a difusão de novos valores na sociedade. Contudo, segundo Roni Barbosa, apenas uma minoria das empresas paranaenses possui códigos de ética. Assim, o exemplo dado não é dos melhores:

"Geralmente, são grandes empresas, em especial as multinacionais, que possuem um código de ética. Mas, eu não vejo a utilização. Muitas vezes, acabam não cumprindo o próprio código de ética. Você vê gerente não agindo de acordo com a conduta ética que a empresa mesmo estabeleceu."

Em suma, nota-se que há uma variedade de opiniões a respeito das conseqüências sociais, diretas e indiretas, da adoção de novas tecnologias e de novos métodos de gestão do trabalho.

Concluindo, os depoimentos das lideranças sindicais entrevistadas sobre questões referentes à manifestação das novas tendências de gestão do trabalho no Brasil permitiram registrar muitas críticas ao discurso empresarial, que enaltece as vantagens dos novos métodos gerenciais para os próprios trabalhadores. Não há espaço, neste artigo, para aprofundar esta discussão. Acredita-se que as falas aqui apresentadas, ao oferecerem um quadro com diferentes visões a respeito da problemática exposta na Introdução, possam estimular mais debates e novas investigações.

\begin{abstract}
The objective of this paper is to present the main arguments of national discussion about the consequences of the introdution of technical inovations and the organisational culture changes to the workers in corporations. The article examines five affirmatives: (i) the technical inovations demand the adoption of flexible workforce management model; (ii) the function of the Human Resources Department is to adapt the employees to the new exigencies of production; (iii) the workforce management in industrial sector is different of workforce management in services sector; (iv) the consequences of flexible workforce management model are unfavourable to corporation employees; (v) the new human resources management induces changes in the social dimension.
\end{abstract}

Key-words: technical inovations; organisational culture; human resources management. 


\section{Referências}

ACKERMAN, M. E. Brevíssima reflexão sobre a formação profissional na cultura dos "recursos humanos". In: DIEESE (org.) Emprego e desenvolvimento tecnológico. São Paulo: Dieese, 1998.

CARVALHO, A. A. FIAT: um novo modelo de qualificação para a competência organizacional? In: CARVALHO NETO, A.M. \& CARVALHO, R. (org.) Sindicalismo e negociação coletiva nos anos 90. Belo Horizonte: IRT/PUCMG, 1998.

CARVALHO NETO, A. M. de \& PARREIRAS DE OLIVEIRA, V. C. Negociações coletivas no setor bancário brasileiro: perdas, resistência e alguns avanços nos anos 90. In: CARVALHO NETO, A. M. \& CARVALHO, R. (org.) Sindicalismo e negociação coletiva nos anos 90. Belo Horizonte: IRT/PUC-MG, 1998.

CASTElls, M. A sociedade em rede. São Paulo: Editora Paz e Terra, 2000.

CHIAVENATO, I. Gestão de pessoas: o novo papel dos recursos humanos nas organizações. Rio de Janeiro: Campus, 2002.

COUTINHO, L. A terceira revolução industrial e tecnológica: as grandes tendências de mudança. Economia e Sociedade, Campinas, Instituto de Economia, n. 1, agosto, 1992.

DEDECCA, C. S. Racionalização econômica e trabalho no capitalismo avançado. Campinas: Unicamp.Instituto de Economia, 1999.

FLEURY, A. et al. Gestão da empresa, automação e competitividade: novos padrões de organização e de relações do trabalho. Organização: Rosa Maria Sales de Melo Soares. Brasilia: IPEA, 1990.

FREYSSINET, J. Mudanças tecnológicas e relações profissionais: experiências sindicais na Europa Ocidental. In: DIEESE (org.) Emprego e desenvolvimento tecnológico. São Paulo: Dieese, 1998.

HIRATA, H. Reorganização da produção e transformações do trabalho: uma perspectiva Norte/Sul. In: CARVALHO NETO, A. M. \& CARVALHO, R. (org.) Sindicalismo e negociação coletiva nos anos 90. Belo Horizonte: IRT/PUCMG, 1998.

IANNI, O. Teorias da globalização. Rio de Janeiro: Civilização Brasileira, 1996.

KARKOTLI, G. \& ARAGÃO, S. D. Responsabilidade social: uma contribuição à gestão transformadora das organizações. Petrópolis, RJ: Vozes, 2004.

MATTOSO, J. A desordem do trabalho. São Paulo: Scritta, 1995.

MEIRELES FILHO, J. Reestruturação produtiva. In: CARVALHO NETO, A. M. \& CARVALHO, R. (org.) Sindicalismo e negociação coletiva nos anos 90. Belo Horizonte: IRT/PUC-MG, 1998.

NERI, A. A. (org.). Gestão de RH por competências e a empregabilidade. Campinas: Papirus, 1999.

NEVES, M. de A. Reestruturação produtiva e estratégias no mundo do trabalho: as consequências para os trabalhadores. In: CARVALHO NETO, A. M. \& CARVALHO, R. (org.) Sindicalismo e negociação coletiva nos anos 90. Belo Horizonte: IRT/PUC-MG, 1998.

SENNETT, R. A corrosão do caráter: consequências pessoais do trabalho no novo capitalismo. Rio de Janeiro: Record, 2000.

WOOD Jr., T. (coordenador). Gestao empresarial: oito propostas para o Terceiro Milênio. São Paulo: Atlas, 2001.

\section{Dados completos do primeiro autor:}

Nome completo: Marcelo Weishaupt Proni 
Filiação Institucional: UNICAMP - SP

Endereço completo para correspondência: UNICAMP (Instituto de Economia, Centro de Estudos Sindicais e de Economia do Trabalho- sala 102, Cidade Universitária, Caixa-Postal: 6135, Campinas - SP - Brasil, CEP 13.083-970

Telefones para contato: (19) 37885807 Fax: (19) 32891565

e-mail: mwproni@eco.unicamp.br

Recebido para publicação em: 17/01/2006

Aceito para publicação em: 10/05/2006 